\title{
Um Assistente Pessoal de Aprendizagem Continuada na WEB
}

\section{Luis Carlos Costa Fonseca}

Orientador(a): Profa. Dra. Rosa Maria Vicari

Coorientador: Prof. Dr. Crediné Silva de Menezes

Data da defesa: 15 de dezembro de 2009

O conhecimento de uma pessoa pode tornar-se obsoleto ou incompleto rapidamente, visto que na chamada sociedade da informação e do conhecimento, a todo instante surgem novas teorias e tecnologias, que são rapidamente publicadas e disseminadas pelos novos meios de comunicação e informação, notadamente a Internet. Visando contribuir para a atenuação desse problema, o presente trabalho propõe o desenvolvimento de um ambiente baseado na Web que dê apoio à aprendizagem continuada de um indivíduo dentro de algum campo de interesse, facilitando, assim, a atualização de seus conhecimentos. Do ponto de vista tecnológico, o trabalho se apóia na recuperação de informações em contexto e na tecnologia de agentes de software; do ponto de vista pedagógico, inspira-se na pedagogia de projetos de aprendizagem.

\section{Referência:}

FONSECA, Luis Carlos Costa. Um Assistente Pessoal de Aprendizagem Continuada na WEB Orientadora: Rosa Maria Vicari. Coorientadora: Crediné Silva de Menezes - 2009. Tese (doutorado) - Programa de Pós-Graduação em Informática na Educação, Centro de Estudos Interdisciplinares em Novas Tecnologias da Educação, Universidade Federal do Rio Grande do Sul, 2009, Porto Alegre. 